\title{
Multivariate control of root biomass in a semi-arid grassland on the Loess Plateau, China
}

\author{
Huoxing Zhu $\cdot$ Bojie Fu • Nan Lv • Shuai Wang • \\ Jian Hou
}

Received: 11 August 2013 / Accepted: 17 February 2014 / Published online: 2 March 2014

(C) Springer International Publishing Switzerland 2014

\begin{abstract}
Aim Root biomass has long been under-represented in biodiversity-ecosystem functioning studies, despite its dominance in biomass in many arid and semi-arid ecosystems. We aimed to explore the multivariate control over root biomass by plant diversity, together with other biotic and abiotic factors and to evaluate the relative importance of these factors.

Methods Above- and below-ground traits of 13 communities and soil properties were measured in semi-arid grasslands on the Loess Plateau, China. Structural equation modeling (SEM) was used to evaluate the relative importance of the community and soil characteristics, emphasizing the direct and indirect effects of plant diversity on root biomass.

Results Significant indirect effects of plant species richness on root biomass were found, although no direct correlation was detected between them. In the indirect pathways, plant species richness showed a positive effect on soil total nitrogen, but a significant negative influence on soil total carbon. Soil total nitrogen and plant diversity had the largest and smallest total effect respectively on root biomass in the model.

Conclusions Plant species richness was not the strongest determinant of root biomass but had a significant
\end{abstract}

Responsible Editor: Kees Jan van Groenigen.

H. Zhu $\cdot$ B. Fu $(\bowtie) \cdot N$. Lv $\cdot$ S. Wang $\cdot$ J. Hou

State Key Laboratory of Urban and Regional Ecology,

Research Center for Eco-Environmental Sciences, Chinese

Academy of Sciences, P. O. Box 2871, Beijing 100085,

People's Republic of China

e-mail: bfu@rcees.ac.cn indirect effect, mediated through soil total carbon and nitrogen. This study suggests that greater plant species richness, through a positive influence on soil total nitrogen, may indirectly promote root carbon stock.

Keywords Plant diversity - Root biomass · Structural equation modeling - Soil carbon sequestration - Soil total nitrogen retention

\section{Introduction}

Root biomass is an important component of ecosystem carbon stock (De Deyn et al. 2008) and a useful predictor for several processes such as soil erosion in many terrestrial ecosystems (Gyssels et al. 2005). Many factors including biotic characteristics, such as plant species composition and diversity, and abiotic conditions, such as nutrient availability, influence the root biomass production (Hooper et al. 2005; Spehn et al. 2005). Understanding the underlying mechanisms for these controls over root biomass is of major interest to predict the capacity of ecosystem carbon sequestration under future global change scenarios (De Deyn et al. 2008), as well as to provide valuable information for more effective erosion controlling practices (Gyssels et al. 2005; Reubens et al. 2007).

Plant diversity plays a key role in determining ecosystem processes such as primary production, nutrient cycling and has received much attention in biodiversity ecosystem functioning (BEF) studies (Naeem et al. 1994; Hooper and Vitousek 1997; 
Huston 1997; Tilman et al. 1997; Hector et al. 1999; Loreau et al. 2001; Hooper et al. 2005; Balvanera et al. 2006; Cardinale et al. 2006). However, many of these previous research efforts used aboveground biomass as a proxy of primary production. Less attempts have been devoted to the diversity effects on root biomass (Lamb 2008), which accounts for more than $60 \%$ of plant biomass in temperate grassland ecosystems (Liira and Zobel 2000) and thus contributes much to ecosystem carbon sequestration in global arid and semi-arid ecosystems.

Recent studies have reported inconsistent relationships between plant diversity and root biomass. For instance, Schmid and Kazda (2002) compared the root biomass of monoculture Norway spruce with that of mixed stands composed of spruce and beech. They found that, although the coarse roots did not differ significantly, the fine root biomass increased markedly in the mixed stand, suggesting that species richness may enhance the production of fine roots. In contrast, a significant relationship between fine root biomass and species richness was not found in 12 temperate deciduous forest stands in central Europe (Meinen et al. 2009). Another related study found a highly variable plant diversity-root biomass relationship, which depends on vegetation type, soil conditions and sometimes root sampling methodology (Spehn et al. 2005). These divergent results demonstrate that the nature of the relationship between root biomass and plant diversity remains unclear.

It is well acknowledged that in addition to plant diversity, other biotic factors interact with abiotic controls, such as climate, geography and soil conditions, to control the biomass production (Hooper et al. 2005; Kahmen et al. 2005; Grace et al. 2007; Tilman et al. 2012). Especially, plant species composition has been identified as one of the strongest control over many ecosystem properties due to the presence of species with particular functional traits which may impose large effects on the ecosystem properties of interest (Chapin et al. 2011). The introduction of a nitrogen fixer into some nitrogen-limited ecosystems, for example, may substantially promote the nitrogen availability and cycling and thereby biomass production in these ecosystems (Vitousek 2004). However, little is known about the relative importance of plant diversity among all these biotic and abiotic controls over ecosystem productivity. Recent studies have begun to explore these relationships. For example, Kahmen et al. (2005) conducted an observational study in semi-natural grassland ecosystems in Europe and found that species diversity had no significant effect on productivity, whereas species composition, soil and site characteristics and the disturbance regime were more powerful determinants of productivity. In contrast, evidence from 11 long term experiments suggested that change in plant diversity had a strong effect, which was not weaker than that of other variables (such as soil $\mathrm{N}$ concentration, grazing intensity and fire regime), on productivity in temperate grassland ecosystems at Cedar Creek in Minnesota, USA (Tilman et al. 2012). Therefore, more studies are needed to identify the relationships between biotic and abiotic factors and ecosystem productivity.

Structural equation modeling (SEM) is an advanced multivariate statistical method which has received increasing attention in recent ecological studies (Malaeb et al. 2000; Grace 2006). This method, compared to traditional univariate methods, is developed to explore the complex networks between variables and thus is particularly suitable for observational studies in ecology (Grace 2006; Grace et al. 2007). Recently, an increasing number of studies have employed this approach to disentangle the intertwined relationships among ecological variables in different ecosystem types and for different ecosystem processes (Grace 2006). For example, Jonsson and Wardle (2010) performed a SEM analysis of the effects of natural disturbance and plant community characteristics on forest carbon storage. They found that wildfire can largely alter belowground carbon storage both directly through humus combustion and indirectly by modifying community diversity and composition. In addition, SEM has also been used in other ecosystem types such as coastal marsh (Grace and Pugesek 1997; Gough and Grace 1999) and for other ecosystem properties (Weiher et al. 2004; Laughlin et al. 2007). All of these diverse applications of SEM suggests that it is a robust and powerful tool for ecological research.

Although numerous studies have been conducted on the relationship between plant diversity and aboveground biomass and some consensus has been achieved (Loreau et al. 2001; Hooper et al. 2005; Cardinale et al. 2006; Balvanera et al. 2006), little is known about the plant diversity effect on root biomass and the relative importance of plant diversity in the presence of other driving factors. The objectives of this study were (1) to determine whether and how plant diversity and other biotic and abiotic factors influence root biomass, and (2) 
to assess the relative importance of these controls over root biomass in semi-arid grassland ecosystems.

\section{Materials and methods}

Study site

The study was conducted in the Yangjuangou catchment $\left(36^{\circ} 42^{\prime} \mathrm{N}, 109^{\circ} 31^{\prime} \mathrm{E}\right)$ located in the middle of the Loess Plateau in Shaanxi Province, China, which is a typical watershed suffering from severe water erosion. It has a semi-arid continental climate, with an average annual precipitation of $535 \mathrm{~mm}$ and an average annual temperature of $14{ }^{\circ} \mathrm{C}$. The soils are Calcaric cambisols, which are nutrient poor and prone to erosion (Liu et al. 2012). The vegetation of the watershed mainly comprises plantation forests dominated by Robinia pseudoacacia and the natural re-vegetation grass Artemisia sacrorum, Stipa bungeana and Artemisia scoparia (Fu et al. 2009). The land use history of the catchment can be divided into three phases: the original natural vegetation phase (before the 1940s) that was dominated by grassland (Jiang et al. 2013), a cultivated land phase (the 1940s-1980s), and a re-vegetation phase (after the 1980s).

\section{Data collection}

The study was conducted as a randomized block design, with the grassland patches being the block factor. Thirteen relatively homogeneous grassland patches ( $\sim 1$ ha per patch) were selected and their geographic information (elevation, altitude and latitude) was recorded using a GPS and topographic variables (slope, aspect) with a compass. Within each patch, different numbers of plots $\left(1 \mathrm{~m}^{2}\right)$ were set up according to the area of the corresponding patch. In total, 350 plots were established. In each plot, we first identified all the species present, documented the average height of each species and visually estimated the percentage cover of each species. Then, we took five soil cores of $20 \mathrm{~cm}$ depth using a soil cylinder and mixed them to give a composite sample, which, after preparation (air-drying and screening through a 100 mesh sieve), was used to determine the soil $\mathrm{C}, \mathrm{N}$ concentrations using an element analyzer (Vario EL Element Analyzer, EVISA, Germany). Finally, roots were sampled by excavation with two additional soil samples of $10 \mathrm{~cm}$ length, $10 \mathrm{~cm}$ width and $20 \mathrm{~cm}$ depth per plot using a soil core and the resulting root samples were washed. The live roots were separated, dried at $60{ }^{\circ} \mathrm{C}$ for $48 \mathrm{~h}$, and weighed on an electronic scale to determine the root biomass.

We calculated the plant species richness and Pielou evenness indices using the Vegan package in R. To analyze compositional differences among the plots, non-metric multidimensional scaling (NMDS) techniques were performed and the scores of the first axes were used in subsequent structural equation model analyses.

In total, seven continuous variables were compiled as follows: (1) plant species richness as the number of vascular plant species in $1 \mathrm{~m}^{2}$ quadrats, (2) plant species evenness as the Pielou Evenness Index calculated from the abundance data collected in $1 \mathrm{~m}^{2}$ quadrats, (3) plant community composition as the scores of the NMDS first axis, (4) plant density as the number of individual vascular plants per $\mathrm{m}^{2}$, (5) root biomass, (6) soil $\mathrm{N}$ concentration, (7) soil $\mathrm{C}$ concentration.

The structural equation model

Prior to data collection, an initial hypothesized structural equation model was established. First, we developed a conceptual model based on our knowledge and previous studies (Loreau et al. 2001; Hooper et al. 2005). The model consisted of three major components: biotic community, abiotic controls and ecosystem properties, interacting with each other (Fig. 1). Then, we converted the conceptual model into a detailed measurement model (Fig. 2). Abiotic controls were represented by soil total nitrogen and carbon concentrations, while biotic controls were represented by plant species richness or evenness, community density, and community composition. Root biomass served as a representation of ecosystem properties. Finally, we developed the detailed model by specifying the pathways among these elements (Fig. 2). Two models, the richness model and the evenness model, were hypothesized because of the critical role of evenness independent of richness (Wilsey et al. 2005). Direct and indirect pathways from plant diversity, species composition, and plant density to root biomass were included in both models.

\section{Statistical analysis}

We performed an ordinary least square regression analysis (OLS) to examine the linearity among these controls and root biomass, because SEM is applicable 
Fig. 1 The conceptual framework of the Structural equation modeling (SEM). Elements in the rectangles represent all the three components of the ecosystem. Both the dotted (not included in the SEM) and solid arrows (included in the SEM) represent interactions between the components

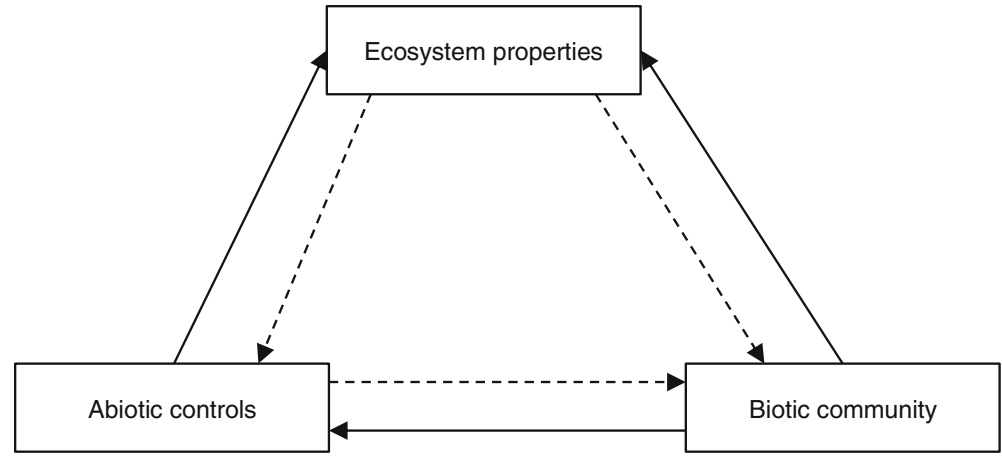

typically when the relationships between the variables considered are linear.

While the initial structural equation models represented our understanding about the relationships, they were unidentified because the number of the parameters to be estimated surpassed that of the sample variance/ covariance. To solve the problem of over parameterization, we removed the path from plant diversity to soil total carbon because removing it improved the overall model fit most among all the paths. The resulting models exhibited good matches with the data.

The hypothesized models were estimated and evaluated using the CALIS procedure (a procedure developed for performing SEM in SAS) in SAS 9.1. Both chi square values and RMSEA (an index for SEM model fit) were calculated to evaluate the overall model fit with the data. We assessed the significance of the path coefficients using t-values, calculated as the path coefficients divided by their standard error because SAS did not provide the p-values. Non-significant pathways were indicated as dotted arrows in the final models (Fig. 4).

\section{Results}

Bivariate relationship

The results of the OLS regression analysis are presented in Fig. 3. Species composition, plant density, and soil total carbon and nitrogen concentrations were all significantly correlated with root biomass, although the relationships were weak and the $\mathrm{R}^{2}$ values were low, ranging from 0.021 for plant density to 0.071 for soil total nitrogen concentrations (Fig. 3). The species richness/ evenness showed no significant linear relationships with

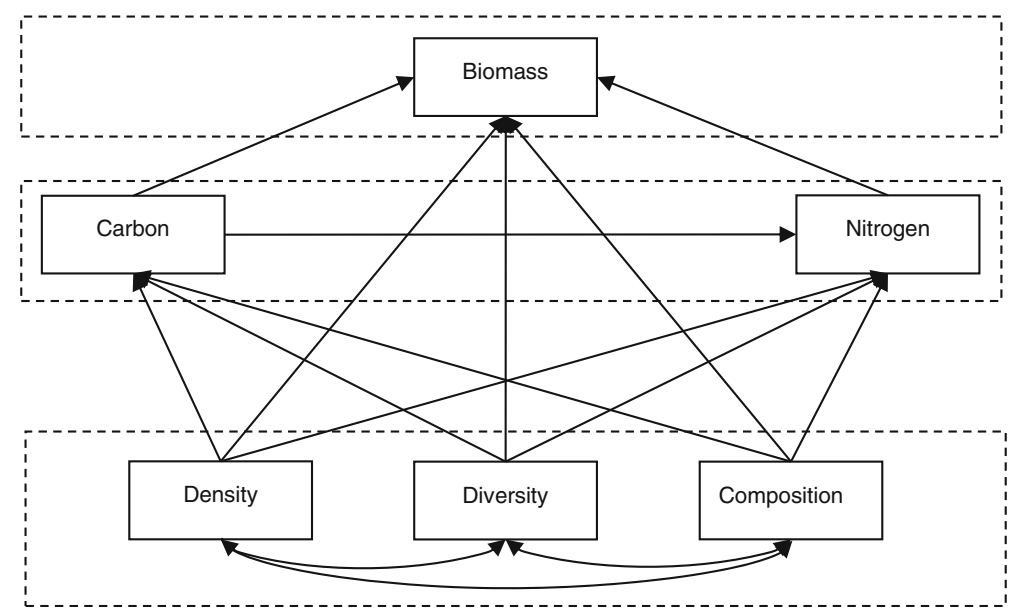

Fig. 2 The initial model based on the conceptual framework. All three components are shown as dotted rectangles, with the top rectangle representing the ecosystem properties and the lowest one the biotic community. All the observed variables are shown as solid rectangles (biomass $=$ root biomass, carbon $=$ soil carbon concentration, nitrogen $=$ soil nitrogen concentration, density $=$ plant density, diversity $=$ species richness/species evenness, composition $=$ species composition). The effects of one variable on another are represented as single arrows. With the correlation between two variables being double arrows 

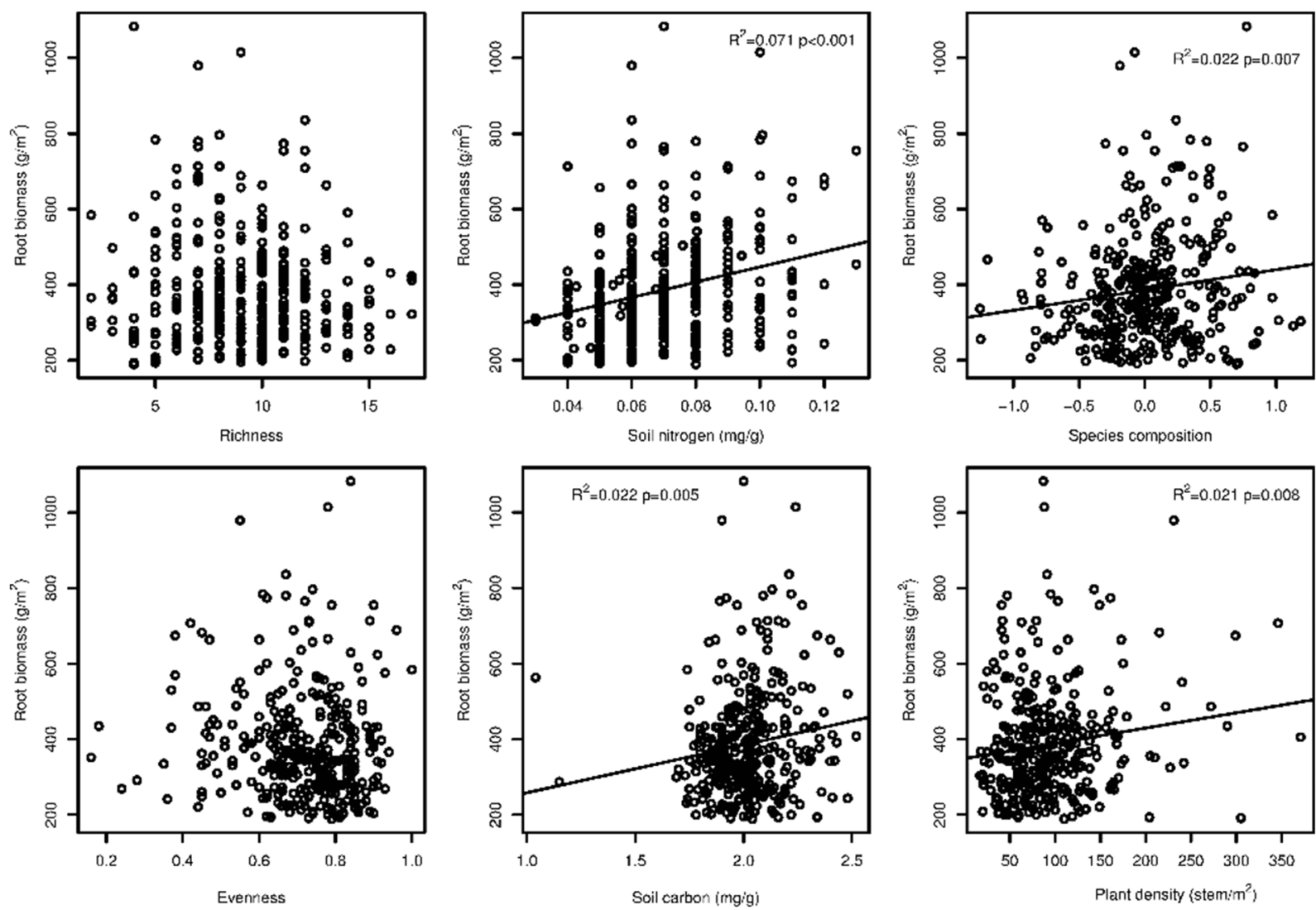

Fig. 3 Bivariate relationships between richness, evenness, soil carbon and nitrogen concentrations, species composition, plant density and root biomass

root biomass. Taken together, these results suggested that SEM is applicable for our system.

\section{Structural equation models}

The final structural equation models are shown in Fig. 4. For the richness model, the direct pathway from richness to the root biomass was not statistically significant. However, there were two indirect pathways in the model which were significant (Pathway 1: from richness via soil total nitrogen to the root biomass, and Pathway 2: from richness via soil total carbon via soil total nitrogen to the root biomass) (Fig. 4a). For the evenness model, none of the direct or indirect pathways between species evenness and root biomass were found to be significant (Fig. 4b). For the two models, both species composition and plant density were significantly positively correlated with root biomass and soil total nitrogen, with the species composition also positively correlated with soil total carbon (Fig. 4). The total, direct and indirect effects of the two models showed a similar pattern, with the strongest control over root biomass being soil total nitrogen and the weakest being plant diversity (Table 1).

The results of the overall model fit, the parameter estimation and the statistical tests are summarized in Table 2. The richness model explained $10.1 \%$ of the variation in root biomass, $39.3 \%$ of the variation in soil total nitrogen and $5.1 \%$ of the variation in soil total carbon, while the evenness model accounted for $10.2 \%$, $38.3 \%$, and $5.5 \%$ of the three variables, respectively.

\section{Discussion}

It was initially hypothesized that plant diversity had a positive effect on root biomass in our initial models. However, no significant correlation between them was found, which is consistent with most of the observational BEF studies (Kahmen et al. 2005; Grace et al. 2007; Lamb 2008). Although many reasons, such as inappropriate method for root sampling (Lamb 2008) and the 
Fig. 4 Final structural equation models for a the richness model and $\mathbf{b}$ the evenness model. Dotted arrows represent non-significant pathways. Standardized coefficients are listed beside each significant pathway

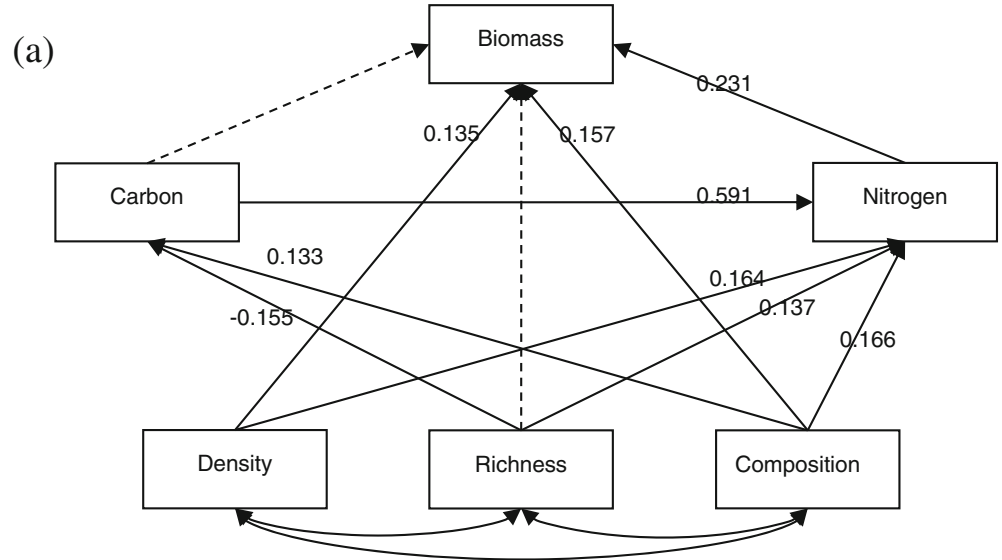

(b)

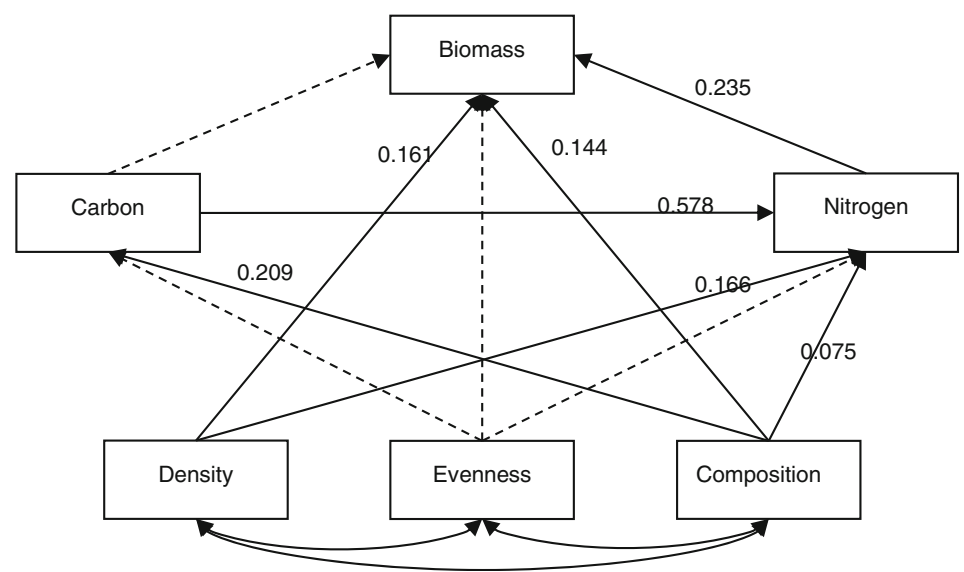

discrepancy between shoot diversity and root diversity (Moore and Field 2005), may be responsible for this non-significant result, it is most likely that the low soil nutrient levels of our system suppress the complementary effect between plant species (He et al. 2002), which is considered to be one effective mechanism for the positive diversity effect (Table 1).

Plant diversity was also hypothesized to enhance root biomass by increasing soil total carbon and nitrogen levels. We found a significant negative effect of plant diversity on soil total carbon, which is largely inconsistent with many related studies on biodiversity and soil total carbon sequestration (Steinbeiss et al. 2008; Saha et al. 2009; Nielsen et al. 2011). This negative result may be explained by both the decrease of total carbon input to and the increase of output from the soil. First, higher plant diversity may lead to decreased litter decomposition thereby maintaining higher standing litter pools (Knops et al. 2001) and thus lower soil total carbon levels. This negative diversity effect likely results from the translocation of inhibitory compounds in litter from one species to another (Hector et al. 2000). Second, higher plant diversity may promote microbial decomposition rates by increasing soil nutrient availability (Wardle et al. 1999; Hooper et al. 2000; Stephan et al. 2000), which could release more soil C into the atmosphere. Collectively, decreasing litter decomposition rates and increasing soil microbial activities may be the major mechanisms for the decreased soil total carbon concentration (Jonsson and Wardle 2010). For soil total nitrogen, the positive plant diversity effect may be explained by integrating the complementary effect with the sampling effect. First, higher plant diversity leads to a more complete use of soil total nitrogen and therefore decreases soil total nitrogen levels. On the other hand, communities with higher plant diversity have the greater probability of containing a nitrogenfixer species and thus increase nitrogen input to soil. 
Table 1 Total, direct and indirect effects in the structural equation models

\begin{tabular}{|c|c|c|c|c|c|c|c|}
\hline & \multicolumn{3}{|c|}{ Richness model } & & \multicolumn{3}{|c|}{ Evenness model } \\
\hline & Total & Direct & Indirect & & Total & Direct & Indirect \\
\hline Biomass $=$ & & & & Biomass= & & & \\
\hline Richness & 0.018 & ns & 0.018 & Evenness & $\mathrm{ns}$ & $\mathrm{ns}$ & $\mathrm{ns}$ \\
\hline Composition & 0.211 & 0.157 & 0.054 & Composition & 0.187 & 0.144 & 0.043 \\
\hline Density & 0.173 & 0.135 & 0.038 & Density & 0.199 & 0.161 & 0.038 \\
\hline Nitrogen & 0.231 & 0.231 & 0.000 & Nitrogen & 0.235 & 0.235 & 0.000 \\
\hline Carbon & 0.136 & ns & 0.136 & Carbon & 0.136 & ns & 0.136 \\
\hline Nitrogen= & & & & Nitrogen $=$ & & & \\
\hline Richness & 0.069 & 0.137 & -0.068 & Evenness & ns & $\mathrm{ns}$ & 0.000 \\
\hline Composition & 0.244 & 0.166 & 0.078 & Composition & 0.196 & 0.075 & 0.121 \\
\hline Density & 0.164 & 0.164 & 0.000 & Density & 0.166 & 0.166 & 0.000 \\
\hline Carbon & 0.591 & 0.591 & 0.000 & Carbon & 0.579 & 0.578 & 0.000 \\
\hline Carbon $=$ & & & & Carbon $=$ & & & \\
\hline Richness & -0.115 & -0.115 & 0.000 & Evenness & ns & ns & 0.000 \\
\hline Composition & 0.133 & 0.133 & 0.000 & Composition & 0.209 & 0.209 & 0.000 \\
\hline
\end{tabular}

The variables in bold with a "=" were the endogenous variables in the models, all other variables are exogenous. The numbers in the table represent the size of the effects, which were calculated using standardized path coefficients. Nonsignificant effects were shown as "ns"

That is, these two effects concurrently determine the soil total nitrogen levels. In our system, many of our communities were at an early successional stage and featured pioneer nitrogen-fixer plants and relatively low plant species richness. These community characteristics favored the sampling effect over the

Table 2 Standardized and unstandardized path coefficients of the structural equation models

\begin{tabular}{|c|c|c|c|c|c|c|c|c|c|}
\hline \multicolumn{5}{|c|}{$\begin{array}{l}\text { Richness model (chi-square }=0.726, \mathrm{df}=1, p=0.394, \\
\text { RMSEA }=0.000)\end{array}$} & \multicolumn{5}{|c|}{$\begin{array}{l}\text { Evenness model (chi-square }=0.136, \mathrm{df}=1, p=0.712 \text {, } \\
\text { RMSEA }=0.000)\end{array}$} \\
\hline Pathways & Unstandardized & Std error & $t$ value & Standardized & Pathways & Unstandardized & Std error & $t$ value & Standardized \\
\hline Biomass $=$ & & & & & Biomass= & & & & \\
\hline Richness & $0.026 \mathrm{~ns}$ & 0.071 & 0.368 & 0.026 & Evenness & $0.046 \mathrm{~ns}$ & 0.062 & 0.743 & 0.046 \\
\hline Composition & 0.157 & 0.072 & 2.191 & 0.157 & Composition & 0.145 & 0.055 & 2.647 & 0.144 \\
\hline Density & 0.135 & 0.054 & 2.509 & 0.135 & Density & 0.161 & 0.064 & 2.523 & 0.161 \\
\hline Nitrogen & 0.232 & 0.066 & 3.494 & 0.231 & Nitrogen & 0.235 & 0.066 & 3.575 & 0.235 \\
\hline Carbon & $-0.015 \mathrm{~ns}$ & 0.066 & -0.229 & -0.015 & Carbon & $-0.015 \mathrm{~ns}$ & 0.065 & -0.226 & -0.015 \\
\hline Nitrogen= & & & & & Nitrogen= & & & & \\
\hline Richness & 0.136 & 0.058 & 2.356 & 0.137 & Evenness & $-0.004 \mathrm{~ns}$ & 0.051 & -0.081 & -0.004 \\
\hline Composition & 0.165 & 0.058 & 2.831 & 0.166 & Composition & 0.075 & 0.045 & 1.673 & 0.075 \\
\hline Density & 0.164 & 0.043 & 3.770 & 0.164 & Density & 0.166 & 0.052 & 3.185 & 0.166 \\
\hline Carbon & 0.588 & 0.044 & 13.489 & 0.591 & Carbon & 0.579 & 0.044 & 13.136 & 0.578 \\
\hline Carbon $=$ & & & & & Carbon= & & & & \\
\hline Richness & -0.115 & 0.072 & -1.599 & -0.115 & Evenness & -0.106 & 0.053 & -1.999 & -0.106 \\
\hline Composition & 0.133 & 0.072 & 1.844 & 0.133 & Composition & 0.209 & 0.053 & 3.947 & 0.209 \\
\hline
\end{tabular}

The overall model fits were also given in the first row of the table. The pathways were indicated by the variables in lower rows to the variables in bold with a "=" in the table. Nonsignificant effects were shown as "ns" 
complementary effect and thus led to the positive effect of plant diversity on soil total nitrogen.

Plant species composition was anticipated to positively correlate with root biomass either directly or indirectly through soil total nitrogen. The SEM results demonstrated that plant species composition enhanced the root biomass through both direct and indirect ways. These results support the general finding that plant species composition may be a more powerful biotic determinant than plant diversity of many ecosystem properties, derived from many experimental and observational studies (Kahmen et al. 2005; Hooper et al. 2005). Plant functional traits of the dominant species are most likely responsible for this strong plant species composition effect. In our system, communities with higher NMDS ordination scores were characterized by the dominance of nitrogen-fixer and species with higher root: shoot ratios. These plant functional traits promoted the nitrogen input to soil and increased the plant biomass allocation to roots, and therefor gave rise to the strong impacts of plant species composition on root biomass.

The total effect analysis suggested that soil total nitrogen levels, and to a lesser extent plant species composition had the largest, while soil total carbon levels and species diversity the smallest, impacts on root biomass. This result is consistent with some of the previous studies (Kahmen et al. 2005; Grace et al. 2007). As Hooper et al. (2005) noted, "abiotic conditions, disturbance regime, and functional traits of dominant plant species may have a greater effect on many ecosystem properties than does plant species richness." This pattern of the relative importance may reflect the dominant role of functional trait among biotic controls, and nutrient availability among abiotic controls, over ecosystem properties.

This study has taken a step in exploring the multivariate control of ecosystem properties, as well as the biodiversity effect in the context of multiple factors. However, plant functional traits and functional diversity have recently been suggested to be a more powerful predictor on ecosystem properties than species diversity (Diaz and Cabido 2001; Lavorel and Garnier 2002). Therefore, incorporating trait-based approaches into the BEF framework may be a promising direction for future researches (Naeem and Wright 2003). Moreover, integrating multiple ecosystem functions (multifunctionality) in future BEF studies may provide a more comprehensive picture of biodiversity, ecosystem functioning and ecosystem services (Maestre et al. 2012a, b).

\section{Conclusion}

This study aimed to explore the direct and indirect effects of plant diversity on root biomass and evaluate the relative importance of related biotic and abiotic factors. Significant indirect effects of plant richness on root biomass were found. Soil total nitrogen and species composition were the strongest biotic and abiotic controls, respectively, on root biomass. In particular, plant diversity may lead to a decrease in soil total carbon under some ecosystem-specific circumstances. These results suggest that plant diversity can play an important role in belowground biomass and may have a complex relationship with soil carbon sequestration in different scenarios. Therefore, this study contributes to more comprehensive biodiversity-ecosystem functioning relationships.

Acknowledgments This work was funded by the National Natural Sciences Foundation of China (No. 41230745) and the CAS/ SAFEA International Partnership Program for Creative Research Teams of "Ecosystem Processes and Services".

\section{References}

Balvanera P, Pfisterer AB, Buchmann N, He JS, Nakashizuka T, Raffaelli D, Schmid B (2006) Quantifying the evidence for biodiversity effects on ecosystem functioning and services. Ecol Lett 9(10):1146-1156. doi:10.1111/j.1461-0248.2006. 00963.x

Cardinale BJ, Srivastava DS, Duffy JE, Wright JP, Downing AL, Sankaran M, Jouseau C (2006) Effects of biodiversity on the functioning of trophic groups and ecosystems. Nature 443(7114):989-992. doi:10.1038/nature05202

Chapin FS, Matson PA, Vitousek PM (2011) Principles of terrestrial ecosystem ecology. Springer, New York

De Deyn GB, Cornelissen JHC, Bardgett RD (2008) Plant functional traits and soil carbon sequestration in contrasting biomes. Ecol Lett 11(5):516-531. doi:10.1111/j.1461-0248. 2008.01164.x

Diaz S, Cabido M (2001) Vive la difference: plant functional diversity matters to ecosystem processes. Trends Ecol Evol 16(11):646-655. doi:10.1016/s0169-5347(01)02283-2

Fu BJ, Wang YF, Lu YH, He CS, Chen LD, Song CJ (2009) The effects of land-use combinations on soil erosion: a case study in the Loess Plateau of China. Prog Phys Geogr 33(6):793804. doi:10.1177/0309133309350264

Gough L, Grace JB (1999) Effects of environmental change on plant species density: comparing predictions with experiments. Ecology 80(3):882-890. doi:10.1890/00129658(1999)080[0882:eoecop]2.0.co;2

Grace JB (2006) Structural equational modeling and natural systems. Cambridge University Press, Cambridge 
Grace JB, Pugesek BH (1997) A structural equation model of plant species richness and its application to a coastal wetland. Am Nat 149(3):436-460. doi:10.1086/285999

Grace JB, Anderson TM, Smith MD, Seabloom E, Andelman SJ, Meche G, Weiher E, Allain LK, Jutila H, Sankaran M, Knops J, Ritchie M, Willig MR (2007) Does species diversity limit productivity in natural grassland communities? Ecol Lett 10(8):680-689. doi:10.1111/j.1461-0248.2007.01058.x

Gyssels G, Poesen J, Bochet E, Li Y (2005) Impact of plant roots on the resistance of soils to erosion by water: a review. Prog Phys Geogr 29(2):189-217. doi:10.1191/ 0309133305pp443ra

He JS, Bazzaz FA, Schmid B (2002) Interactive effects of diversity, nutrients and elevated $\mathrm{CO}(2)$ on experimental plant communities. Oikos 97(3):337-348. doi:10.1034/j.16000706.2002.970304.x

Hector A, Schmid B, Beierkuhnlein C, Caldeira MC, Diemer M et al (1999) Plant diversity and productivity experiments in European grasslands. Science 286(5442):1123-1127. doi:10. $1126 /$ science. 286.5442 .1123

Hector A, Beale AJ, Minns A, Otway SJ, Lawton JH (2000) Consequences of the reduction of plant diversity for litter decomposition: effects through litter quality and microenvironment. Oikos 90(2):357-371. doi:10.1034/j.1600-0706. 2000.900217.x

Hooper DU, Vitousek PM (1997) The effects of plant composition and diversity on ecosystem processes. Science 277(5330): 1302-1305. doi:10.1126/science.277.5330.1302

Hooper DU, Bignell DE, Brown VK, Brussaard L, Dangerfield JM, Wall DH, Wardle DA, Coleman DC, Giller KE, Lavelle P, Van der Putten WH, De Ruiter PC, Rusek J, Silver WL, Tiedje JM, Wolters V (2000) Interactions between aboveground and belowground biodiversity in terrestrial ecosystems: patterns, mechanisms, and feedbacks. Bioscience 50(12):1049-1061. doi:10.1641/0006-3568(2000) 050[1049:ibaabb]2.0.co;2

Hooper DU, Chapin FS, Ewel JJ, Hector A, Inchausti P, Lavorel S, Lawton JH, Lodge DM, Loreau M, Naeem S, Schmid B, Setala H, Symstad AJ, Vandermeer J, Wardle DA (2005) Effects of biodiversity on ecosystem functioning: a consensus of current knowledge. Ecol Monogr 75(1):3-35. doi:10. 1890/04-0922

Huston MA (1997) Hidden treatments in ecological experiments: re-evaluating the ecosystem function of biodiversity. Oecologia 110(4):449-460. doi:10.1007/s004420050180

Jiang WY, Cheng YF, Yang XX, Yang SL (2013) Chinese Loess Plateau vegetation since the Last Glacial Maximum and its implications for vegetation restoration. J Appl Ecol 50(2): 440-448. doi:10.1111/1365-2664.12052

Jonsson M, Wardle DA (2010) Structural equation modelling reveals plant-community drivers of carbon storage in boreal forest ecosystems. Biol Lett 6(1):116-119. doi:10.1098/rsbl. 2009.0613

Kahmen A, Perner J, Audorff V, Weisser W, Buchmann N (2005) Effects of plant diversity, community composition and environmental parameters on productivity in montane European grasslands. Oecologia 142(4):606-615. doi:10.1007/s00442004-1749-2

Knops JMH, Wedin D, Tilman D (2001) Biodiversity and decomposition in experimental grassland ecosystems. Oecologia 126(3):429-433. doi:10.1007/s004420000537
Lamb EG (2008) Direct and indirect control of grassland community structure by litter, resources, and biomass. Ecology 89(1):216-225. doi:10.1890/07-0393.1

Laughlin DC, Abella SR, Covington WW, Grace JB (2007) Species richness and soil properties in Pinus ponderosa forests: a structural equation modeling analysis. J Veg Sci 18(2): 231-242. doi:10.1111/j.1654-1103.2007.tb02534.x

Lavorel S, Garnier E (2002) Predicting changes in community composition and ecosystem functioning from plant traits: revisiting the Holy Grail. Funct Ecol 16(5):545-556. doi: 10.1046/j.1365-2435.2002.00664.x

Liira J, Zobel K (2000) The species richness-biomass relationship in herbaceous plant communities: what difference does the incorporation of root biomass data make? Oikos 91(1):109114. doi:10.1034/j.1600-0706.2000.910109.x

Liu Y, Fu BJ, Lu YH, Wang Z, Gao GY (2012) Hydrological responses and soil erosion potential of abandoned cropland in the Loess Plateau, China. Geomorphology 138(1):404- 414. doi:10.1016/j.geomorph.2011.10.009

Loreau M, Naeem S, Inchausti P, Bengtsson J, Grime JP, Hector A, Hooper DU, Huston MA, Raffaelli D, Schmid B, Tilman D, Wardle DA (2001) Ecology-biodiversity and ecosystem functioning: current knowledge and future challenges. Science 294(5543):804-808. doi:10.1126/science. 1064088

Maestre FT, Castillo-Monroy AP, Bowker MA, Ochoa-Hueso R (2012a) Species richness effects on ecosystem multifunctionality depend on evenness, composition and spatial pattern. J Ecol 100(2):317-330. doi:10.1111/j.13652745.2011.01918.x

Maestre FT, Quero JL, Gotelli NJ, Escudero A, Ochoa V et al (2012b) Plant species richness and ecosystem multifunctionality in global drylands. Science 335(6065): 214-218. doi:10.1126/science.1215442

Malaeb ZA, Summers JK, Pugesek BH (2000) Using structural equation modeling to investigate relationships among ecological variables. Environ Ecol Stat 7(1):93-111. doi:10. 1023/a:1009662930292

Meinen C, Hertel D, Leuschner C (2009) Biomass and morphology of fine roots in temperate broad-leaved forests differing in tree species diversity: is there evidence of below-ground overyielding? Oecologia 161(1):99-111. doi:10.1007/ s00442-009-1352-7

Moore LA, Field CB (2005) A technique for identifying the roots of different species in mixed samples using nuclear ribosomal DNA. J Veg Sci 16(1):131-134. doi:10.1111/j.1654-1103. 2005.tb02346.x

Naeem S, Wright JP (2003) Disentangling biodiversity effects on ecosystem functioning: deriving solutions to a seemingly insurmountable problem. Ecol Lett 6(6):567-579. doi:10. 1046/j.1461-0248.2003.00471.x

Naeem S, Thompson LJ, Lawler SP, Lawton JH, Woodfin RM (1994) Declining biodiversity can alter the performance of ecosystems. Nature 368(6473):734-737. doi:10.1038/ $368734 \mathrm{a} 0$

Nielsen UN, Ayres E, Wall DH, Bardgett RD (2011) Soil biodiversity and carbon cycling: a review and synthesis of studies examining diversity-function relationships. Eur J Soil Sci 62(1):105-116. doi:10.1111/j.1365-2389.2010.01314.x

Reubens B, Poesen J, Danjon F, Geudens G, Muys B (2007) The role of fine and coarse roots in shallow slope stability and soil erosion control with a focus on root system architecture: a 
review. Trees Struct Funct 21(4):385-402. doi:10.1007/ s00468-007-0132-4

Saha SK, Nair PKR, Nair VD, Kumar BM (2009) Soil carbon stock in relation to plant diversity of homegardens in Kerala, India. Agrofor Syst 76(1):53-65. doi:10.1007/s10457-0099228-8

Schmid I, Kazda M (2002) Root distribution of Norway spruce in monospecific and mixed stands on different soils. For Ecol Manag 159(1-2):37-47. doi:10.1016/s0378-1127(01)00708-3

Spehn EM, Hector A, Joshi J, Scherer-Lorenzen M, Schmid B et al (2005) Ecosystem effects of biodiversity manipulations in European grasslands. Ecol Monogr 75(1):37-63. doi:10. 1890/03-4101

Steinbeiss S, Bessler H, Engels C, Temperton VM, Buchmann N, Roscher C, Kreutziger Y, Baade J, Habekost M, Gleixner G (2008) Plant diversity positively affects short-term soil carbon storage in experimental grasslands. Glob Chang Biol 14(12):2937-2949. doi:10.1111/j.13652486.2008.01697.x

Stephan A, Meyer AH, Schmid B (2000) Plant diversity affects culturable soil bacteria in experimental grassland communities. J Ecol 88(6):988-998. doi:10.1046/j.1365-2745.2000. 00510.x
Tilman D, Knops J, Wedin D, Reich P, Ritchie M, Siemann E (1997) The influence of functional diversity and composition on ecosystem processes. Science 277(5330):1300-1302. doi: 10.1126/science. 277.5330 .1300

Tilman D, Reich PB, Isbell F (2012) Biodiversity impacts ecosystem productivity as much as resources, disturbance, or herbivory. Proc Natl Acad Sci U S A 109(26):10394-10397. doi:10.1073/pnas.1208240109

Vitousek PM (2004) Nutrient cycling and limitation: Hawai'i as a model system. Princeton University Press, Princeton

Wardle DA, Bonner KI, Barker GM, Yeates GW, Nicholson KS, Bardgett RD, Watson RN, Ghani A (1999) Plant removals in perennial grassland: vegetation dynamics, decomposers, soil biodiversity, and ecosystem properties. Ecol Monogr 69(4): 535-568

Weiher E, Forbes S, Schauwecker T, Grace JB (2004) Multivariate control of plant species richness and community biomass in blackland prairie. Oikos 106(1):151-157. doi:10.1111/j. 0030-1299.2004.12545.x

Wilsey BJ, Chalcraft DR, Bowles CM, Willig MR (2005) Relationships among indices suggest that richness is an incomplete surrogate for grassland biodiversity. Ecology 86(5): 1178-1184. doi:10.1890/04-0394 